\title{
Alexandre Kiss
}

\section{Droit international de l'environnement}

Etudes Internationales No. 3, Editions A. Pedone, Paris, 1989, 349 S., FF 240,--

Das internationale Umweltrecht (IUR) gehört zu einem der am schnellsten wachsenden Bereiche des Völkerrechts. Hierin spiegelt sich nicht zuletzt der grundlegende Wandel der internationalen Beziehungen wider, welche aufgrund der sich herausbildenden grenzüberschreitenden bis globalen ökologischen Interdependenz und der zunehmenden Wahrnehmung dieser Interdependenz durch die politischen Akteure des internationalen Systems immer mehr den Charakter weltweiter Vergesellschaftung annehmen. A. Kiss gehört zu denjenigen Völkerrechtlem, welche diesen Wandel und auch die Implikationen für das Völkerrecht frühzeitig erkannt und diskutiert haben (man vergleiche seine zusammen mit D. Shelton im Netherlands Yearbook of International Law XVII, 1986, 45-74, veröffentlichten Beitrag unter dem Titel: "Systems analysis of intemational law. A methodological inquiry"). Als Directeur de recherche am C.N.R.S. in Paris und Professor in Santa Clara, Kalifornien, sowie Präsident des Conseil européen du droit de l'environnement ist er auch wie wenige andere kompetent, einen Gesamtüberblick über das IUR zu geben und damit eine echte Marktlücke zu schließen.

Nach einer Abgrenzung des Gegenstands und einer kurzen Geschichte der Entwicklung des IUR (die durch eine Chronologie am Ende des Buches ergänzt wird, welche bis zum 1. November 1988 reicht), bietet Kiss einen Überblick über die Quellen des IUR und wendet sich dann speziell der - immer noch weitgehend ungeregelten - Frage der internationalen Verantwortung für Umweltschäden zu ("aucun texte international ne donne des précisions sur la portée du principe de la responsabilité internationale appliquée à des dommages à l'environnement"; 116). Es folgt ein ausführliches Kapitel über den sektoralen internationalen Umweltschutz (Schutz der Meeresumwelt, der kontinentalen Gewässer, der Luft, der wilden Natur) und ein Kapitel über die grenzüberschreitenden "Querschnitts"Probleme und ihre Verregelung (giftige und gefährliche Stoffe und Abfälle, ionisierende Strahlung und radioaktive Abfälle). Der Band schließt mit einem Überblick über die internationalen Institutionen und ihren Beitrag zur Entwicklung des IUR. Die Mehrzahl der Kapitel wird durch eine Kurzbibliographie ergänzt, der Gebrauchswert des Buches durch einen Sachindex erhöht. Insgesamt ist somit ein vorzügliches Handwerkszeug für die juristische, aber auch politikwissenschaftliche Analyse der internationalen Verregelung von Umweltschutzfragen entstanden, das in jede völker- und umweltrechtliche Bibliothek gehört, darüber hinaus jedoch auch für Bibliotheken der Disziplin der Internationalen Beziehungen eine Bereicherung darstellt. 